\title{
Powder for Syrup Dosage Form
}

National Cancer Institute

\section{Source}

National Cancer Institute. Powder for Syrup Dosage Form. NCI Thesaurus. Code C149854.

Solid preparation consisting of one or more powders that may include excipients to facilitate dissolution in water and to obtain the characteristics of a syrup, intended to be dissolved in water to obtain a syrup. 